\title{
MACHO OU FÊMEA? COMO O SEXO DOS VERTEBRADOS É DETERMINADO
}

Marcos Antonio de Oliveira ${ }^{1^{*}}$

\section{RESUMO}

A reprodução sexual é a forma de propagação mais antiga e universal utilizada pelos vertebrados. Os mecanismos que controlam a determinação e diferenciação sexual nestes animais são diversos e dependem de uma grande variedade de fatores genéticos bem como em alguns casos de fatores ambientais. $\mathrm{O}$ sexo genético pode ser definido por fatores genéticos hereditários que são determinados na fecundação. Por outro lado, a diferenciação gonadal depende da ativação de fatores transcricionais que são expressos durante a janela de diferenciação sexual. Tais fatores podem ter sua expressão alterada por condições ambientais como a temperatura e a osmolaridade, dentre outros. Estes processos sexuais são classicamente divididos em determinação e diferenciação sexual, respectivamente. Baseados em tais fatos, esta revisão tem como objetivo mostrar a fundamentação básica dos processos de determinação e diferenciação sexual em vertebrados com ênfase no grupo dos peixes teleósteos.

Palavras-chave: determinação e diferenciação sexual, desenvolvimento gonadal, gônada, genes, peixes.

\section{MALE OR FEMALE? HOW THE VERTEBRATE SEX ARE DETERMINED}

\begin{abstract}
Sexual reproduction is the oldest and universal form of propagation used by vertebrates. The mechanisms that control sexual determination and differentiation in these animals are diverse and depend on a wide variety of genetic factors as well as in some cases environmental factors. Genetic sex can be defined by hereditary genetic factors that are determined in fertilization. On the other hand, gonadal differentiation depends on the activation of transcriptional factors that are expressed during the sexual differentiation window. Such factors may have their expression altered by environmental conditions such as temperature and osmolarity, among others. These sexual processes are classically divided into sexual determination and differentiation, respectively. Based on such facts, this review aims to show the basic theoretical reasoning of the processes of sexual determination and differentiation in vertebrates, emphasizing the group of teleost fishes.
\end{abstract}

Keywords: sexual determination and differentiation, gonadal development, gonad, genes, fish.

\section{¿MACHO O HEMBRA? CÓMO SE DETERMINA EL SEXO DE LOS VERTEBRADOS.}

\section{RESUMEN}

La reproducción sexual es la forma de propagación más antigua y universal utilizada por los vertebrados. Los mecanismos que controlan la determinación sexual y la diferenciación en estos animales son diversos y dependen de una amplia variedad de factores genéticos, así como en algunos casos de factores ambientales. El sexo genético puede definirse por factores

\footnotetext{
${ }^{1}$ Instituto Federal de Educação Ciência e Tecnologia de Rondônia. *Correspondência: marcos.antonio@ifro.edu.br
} 
genéticos hereditarios que se determinan en la fertilización. Por otro lado, la diferenciación gonadal depende de la activación de factores transcripcionales que se expresan durante la ventana de diferenciación sexual. Dichos factores pueden tener su expresión alterada por condiciones ambientales como la temperatura y la osmolaridad, entre otros. Estos procesos sexuales se dividen clásicamente en determinación y diferenciación sexual, respectivamente. Con base en tales hechos, esta revisión tiene como objetivo mostrar los fundamentos básicos de los procesos de determinación y diferenciación sexual en vertebrados, enfatizando el grupo de peces teleósteos.

Palabras clave: Determinación y diferenciación sexual, desarrollo gonadal, gónada, genes, peces.

\section{INTRODUÇÃO}

No reino animal, a reprodução sexual é a forma de propagação mais antiga e universal utilizada pelos vertebrados. Os mecanismos que controlam a determinação e diferenciação sexual nestes animais são diversos e sofrem a ação de uma grande variedade de fatores genéticos bem como em alguns casos de fatores ambientais $(1,2)$.

$\mathrm{O}$ sexo genético pode ser definido por fatores genéticos hereditários (XX/XY e ZZ/ZW, dentre outros) que são determinados na fecundação. Já, por outro lado, a diferenciação depende da ativação de fatores transcricionais que são expressos durante a janela de diferenciação sexual (3-5). Tais fatores podem ter sua expressão alterada por condições ambientais como a temperatura e a osmolaridade, dentre outros. Estes processos sexuais são classicamente divididos em determinação e diferenciação sexual, respectivamente (1,3-6).

A determinação sexual pode ser definida como um fator herdado, geralmente associado a um gene "master". Este gene inicia e ativa a cascata gênica/bioquímica que culmina na diferenciação das células somáticas presentes na gônada indiferenciada $(5,7,8)$. Apesar de conservados, uma diversidade de genes "masters", cruciais para a determinação sexual, são encontrados em diferentes organismos e todos estes genes são duplicados ou parálogos aos seus ancestrais $(8,9)$. Uma vez ativa, esta cascata será responsável pela regulação de diferentes genes, produção e liberação de hormônios esteroides que culminará na diferenciação da gônada indiferenciada. $\mathrm{O}$ fato da gônada indiferenciada vir a se tornar um testículo ou um ovário é uma etapa importante no processo de diferenciação sexual dos vertebrados $(5,6,8-10)$. No campo da biologia reprodutiva, a elucidação dos vários aspectos envolvidos nos mecanismos de determinação e diferenciação sexual sempre despertou o interesse dos pesquisadores. Sendo assim, o objetivo desta revisão é apresentar o processo de determinação e diferenciação sexual nos vertebrados, em especial nos peixes teleósteos com ênfase na ação dos genes que apresenta importante papel nestes dois processos.

Para identificar os estudos que abordavam o tema, foram realizadas buscas sistematizadas nas bases de dados eletrônicas (https://pubmed.ncbi.nlm.nih.gov/; https://scielo.org/; https://scholar.google.com.br/?hl=pt). Os termos de busca utilizados para a seleção e escolha dos artigos nas bases de dados foram: "Dmrt1, sex determination and differentiation, gonadal development, sexual development, bipotential gonad, teleost fish, vertebrate sex-determining genes, master regulatory gene”. As buscas não foram limitadas por língua ou data de publicação. A última busca foi realizada em fevereiro de 2021. Para a seleção dos estudos, utilizou-se como critério de inclusão estudos completos realizados com peixes teleósteos, tanto modelos biológicos como peixes de produção. A avaliação foi realizada por meio de títulos, seguida por resumos, e quando selecionados, por leitura completa dos artigos. 


\section{Determinação e diferenciação sexual em vertebrados}

Em alguns vertebrados, principalmente os mamíferos, a determinação e diferenciação inicia-se na gônada com a ação de fatores de crescimento e hormônios. Em muitos mamíferos, sabe-se que o processo de determinação sexual envolve o cromossomo Y, o qual contém em seu braço curto o gene responsável pela determinação sexual, conhecido como $S R Y$. Este gene regula positivamente a transcrição de genes masculinos específicos (SOX9 e DMRT1) nas células somáticas da gônada XY (11). A ausência do gene $S R Y$ induz à feminilização, ativando genes ovarianos específicos, como o RSPOL, WNT4 e FOXL2 (11). Em relação a este caso paradigmático, uma vez que o sexo foi determinado, segue-se o caminho de diferenciação, produzindo testículo ou ovário (11-13) (Figura 1).

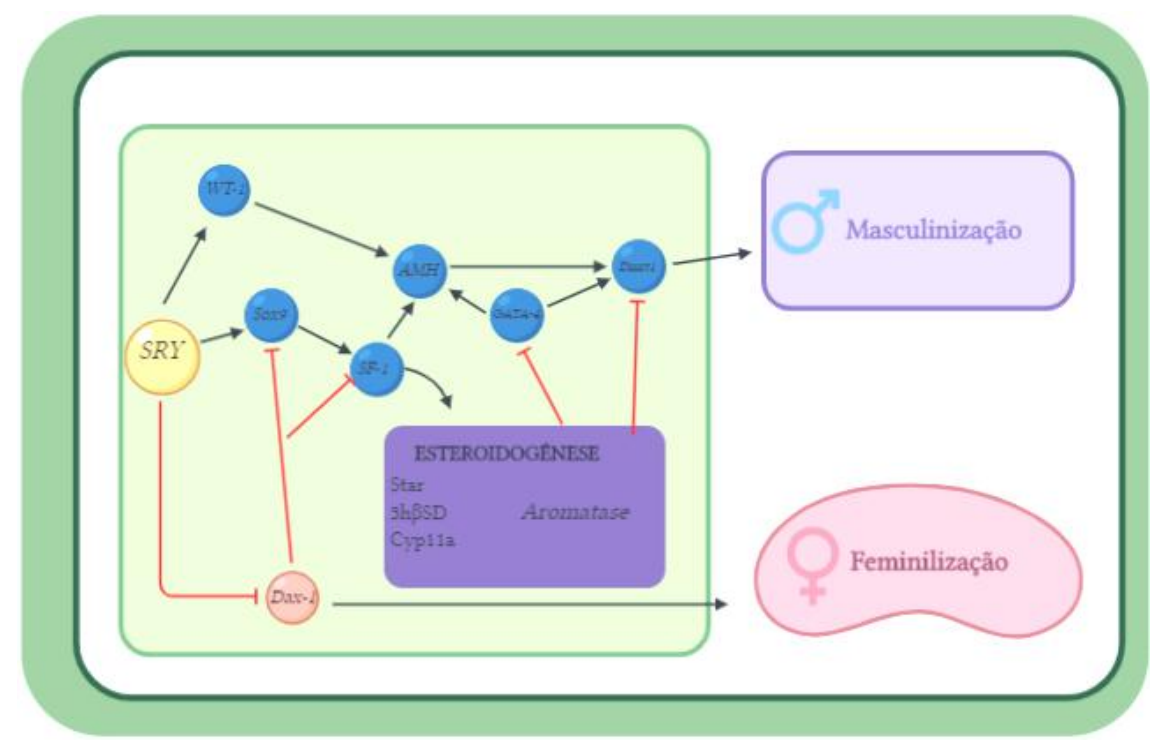

Figura 1. Genes responsáveis pela diferenciação sexual em mamíferos. Em animais vertebrados $\mathrm{XX} / \mathrm{XY}$, o gene $S R Y$ é responsável pela determinação sexual masculina. Quando na ausência do $S R Y$, ocorre à ativação do gene $D A X-1$, o qual será responsável pela diferenciação da gônada feminina. A presença do $S R Y$ resulta na ativação de uma cascata gênica que leva ao desenvolvimento do testículo. $\mathrm{O}$ gene $S F-1$ apresenta um importante papel na esteroidegênese e o $A M H$ desempenha papel chave na diferenciação sexual. A aromatase atua inibindo a expressão do $A M H$ e DMRT1. Setas em preto indicam estimulação. Linhas em vermelho com barra indicam inibição. Modificado a partir de von Hofsten e Olsson (1).

Em anfíbios, o sistema de determinação sexual é complexo, pois espécies como a Rana rugosa, apresentam dois sistemas de determinação sexual, XX/XY e ZZ/ZW $(2,14)$. Por outro lado, em Xenopus tropicalis, Rocco e colaboradores (15) mostraram a existência de três tipos de cromossomos sexuais ( $\mathrm{Y}, \mathrm{W}$ e $\mathrm{Z}$ ). Neste sistema, três tipos de machos podem ser encontrados, YZ, YW e ZZ, enquanto que as fêmeas podem ser ZW ou WW (15). No entanto, a diferenciação sexual em anfíbios pode acontecer das seguintes maneiras: desenvolvimento direto da gônada bipotencial em testículo ou ovário; desenvolvimento da gônada bipotencial passando por um hermafroditismo sequencial e animais com intersexo (2).

Em relação aos genes "masters", o gene dmrtl em Xenopus laevis, surge como um potencial candidato envolvido na determinação e diferenciação sexual. Nestes animais, uma duplicação do gene no cromossomo $\mathrm{W}$ atua como determinante sexual feminino $(2,16)$.

Oliveira MA. Macho ou fêmea? Como o sexo dos vertebrados é determinado. Vet. e Zootec. 2021; v28: 001013. 
Em aves, o mecanismo de determinação sexual é ligado a cromossomos sexuais e neste caso o sistema predominante é o ZZ/ZW. O sistema sexual é homogamético para machos (ZZ) e heterogâmico nas fêmeas (ZW) (17). Nestes vertebrados, uma região conservada no cromossomo $\mathrm{Z}$ é responsável pela determinação sexual masculina e diferenciação testicular, pela regulação do gene $D M R T 1$, que aparentemente não é o gene "master" nesta espécie $(18,19)$.

O processo de determinação e diferenciação sexual em vertebrados foram os assuntos mais debatidos entre os cientistas nos últimos anos. Informações sobre a influências de hormônios, fatores ambientais e principalmente os mecanismos moleculares/genéticos envolvidos nestes processos foram elucidados e com isso foi mostrado a importância de uma gama de genes que participam destes processos, dentre eles, o gene Dmrt1.

\section{Dmrt1 na determinação e diferenciação sexual}

O gene Dmrt1 (Doublesex and mab-3 related transcription factor 1) é um fator de transcrição, conservado entre os vertebrados que desempenha importante papel durante a determinação e diferenciação sexual $(3,20)$ e são caracterizadas por um padrão de ligação de DNA com domínio rico em cisteína, o domínio DM (Doublesex and Mab-3 related) (20,21). O Dmrtl é expresso nas gônadas dos vertebrados, desempenhando papel importante na diferenciação testicular $(3,11,20)$.

Em mamíferos, a determinação sexual ocorre com a expressão do gene "master" SRY. Após a expressão do $S R Y$ a cascata gênica de diferenciação sexual é ativada em que o $D M R T 1$ é expresso na gônada indiferenciada e é responsável pela diferenciação testicular (Figura 1) (20-22).

Em aves, a expressão do DMRT1 é ligada ao cromossomo Z. Portanto os machos possuem duas cópias e as fêmeas uma, sugerindo assim, que a expressão do DMRT1 é essencial para diferenciação testicular e sua alta expressão pode determinar o sexo (18). Já em anfíbios, no caso Xenopus laevis, uma duplicação do dmrtl no cromossomo W é responsável pela diferenciação ovariana (16).

Em alguns peixes o dmrtl é expresso nas gônadas de várias espécies. Em truta arco-íris (Oncorhynchus mykiss), o dmrt1 é expresso nas gônadas masculinas e atua na diferenciação sexual masculina (23). Em tilápia (Oreochromis niloticus), o padrão e expressão do dmrt1 sugere que este gene seja responsável pela diferenciação testicular (24). Já em zebrafish (Danio reiro), Guo e colaboradores (25), mostraram que o dmrt1 não apresenta dimorfismo sexual quanto à sua expressão em gônadas indiferenciadas. Os autores sugerem que este gene desempenha um papel importante durante o desenvolvimento gonadal de machos e fêmeas (25). No entanto, Webster e colaboradores (26) demonstraram em zebrafish que o dmrtl é necessário para o desenvolvimento testicular. Além disso, estes autores também mostraram que o dmrtl é requerido para a manutenção e auto-renovação das células germinativas masculinas iniciais de zebrafish (26). Corroborando estas evidências, a deleção do gene $d m r t 1$ em zebrafish alterou o desenvolvimento das células germinativas, levando à regressão dos testículos (27).

Um dos casos mais interessantes em que o gene dmrt1 atua no processo de determinação sexual em peixes ocorre em medaka (Oryzias latipes). O medaka é uma espécie com o sistema de determinação sexual genética $\mathrm{XX} / \mathrm{XY}$. Uma região específica do cromossomo $\mathrm{Y}$ apresenta o gene $d m Y$ (28) ou também conhecido como dmrt1bY (29). Este gene é formado a partir da duplicação do dmrt1 autossômico. Desta forma, o dmY/dmrt1bY assume o papel primordial de gene "master" de determinação sexual masculina e é necessário para o desenvolvimento testicular $(28,29)$. 
Estes dados mostram que a função do gene Dmrtl é conservado entre os vertebrados e que sua expressão possui um papel essencial para a formação e desenvolvimento testicular.

\section{Determinação e diferenciação sexual em peixes teleósteos}

Os peixes são excelentes modelos biológicos para se estudar a determinação e diferenciação sexual, devido a uma característica muito importante adquirida ao longo de sua evolução, à plasticidade gonadal e reversão sexual funcional (gônada funcional) que ocorre em muitas espécies (7).

Os peixes apresentam uma grande variedade de mecanismos de determinação sexual. Neste sentido, muitas espécies apresentam o sistema de determinação ligado a cromossomos sexuais/heteromórficos $(\mathrm{XX} / \mathrm{XY}$ e $\mathrm{ZZ/ZW)} \mathrm{(7,30).} \mathrm{Por} \mathrm{outro} \mathrm{lado,} \mathrm{em} \mathrm{espécies} \mathrm{de} \mathrm{peixes}$ como O. latipes (31), O. mykiss $(32,33)$ e O. niloticus (34), os machos são heterogâmicos (XY). Já em Oreochromis aureus (35), Xiphophorus maculatus, e Gambusia affinis (36), as fêmeas são heterogâmicas, ZW. Além disso, os peixes apresentam ainda uma grande variedade de mecanismos que podem atuar na diferenciação do sexo. Esta variedade pode ser considerada como estratégias sexuais para reprodução, tais como: animais gonocorísticos (apresentam os sexos separados); animais unissexo (todos são fêmeas ou todos são machos); animais hermafroditas, que podem ser classificados em: hermafrodita sequencial, serial ou simultâneo $(6,37,38)$ (Figura 2).
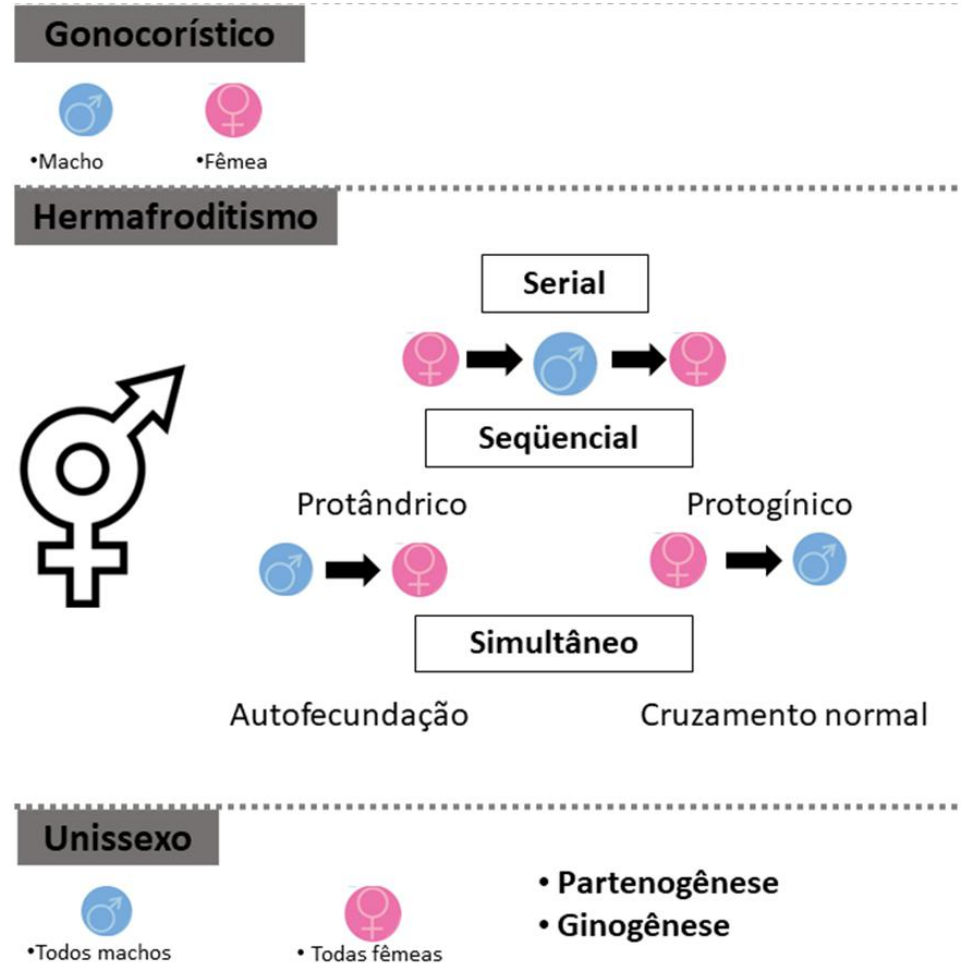

Figura 2. Alguns peixes podem ser: gonocoristícos (apresentam os sexos separados, macho ou fêmea); hermafroditas, que podem ser classificados em hermafrodita serial (primeiro o animal é uma fêmea, ao longo da vida se tornam machos e, outros permanecem fêmeas), sequencial (podendo ser protândrico, em que o animal nasce macho e transforma em fêmea e, protogínico, em que o animal nasce fêmea e se torna macho) e hermafroditismo simultâneo onde ocorrem a auto-fecundação e ou cruzamento normal. Também existem animais unissexo (todos são fêmeas ou todos são machos). Adaptado de Heule (6). 
Esta variedade de mecanismos de diferenciação sexual, podem ser influenciados por uma grande variedade de fatores extrínsecos tais como a temperatura, exposições a hormônios, pH da água, concentração de oxigênio, densidade de estocagem e poluentes, bem como por fatores intrínsecos à exemplo do status social e crescimento (34,37,39-41) (Figura 3). Estes fatores regulam o fenótipo sexual dos peixes podendo em muitos casos ocasionar reversão sexual.

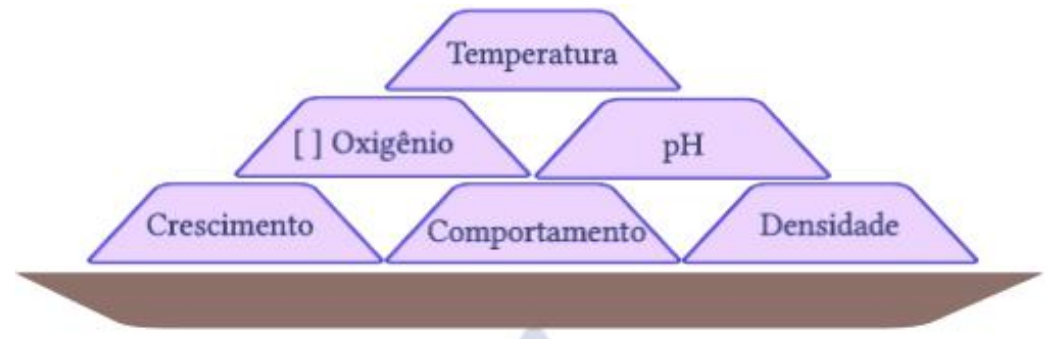

Figura 3. Balança dos fatores que podem influenciar na diferenciação sexual em peixes. Fatores que atuam diretamente regulando o fenótipo sexual dos peixes. Figura: Desenho pessoal.

Conforme se observa nos peixes teleósteos, o processo de diferenciação sexual começa na gônada indiferenciada. A gônada indiferenciada é composta por células somáticas e células germinativas, sendo as últimas responsáveis pela formação dos gametas após a puberdade. No estágio de diferenciação sexual, as células somáticas se diferenciam em células de Sertoli e Leydig nos machos, ou em células da granulosa e da teca nas fêmeas (7). Os componentes germinativos são derivados muito precocemente das células germinativas primordiais (PGC), as quais migram para a gônada primitiva (42-44) conforme nota-se na Figura 4.

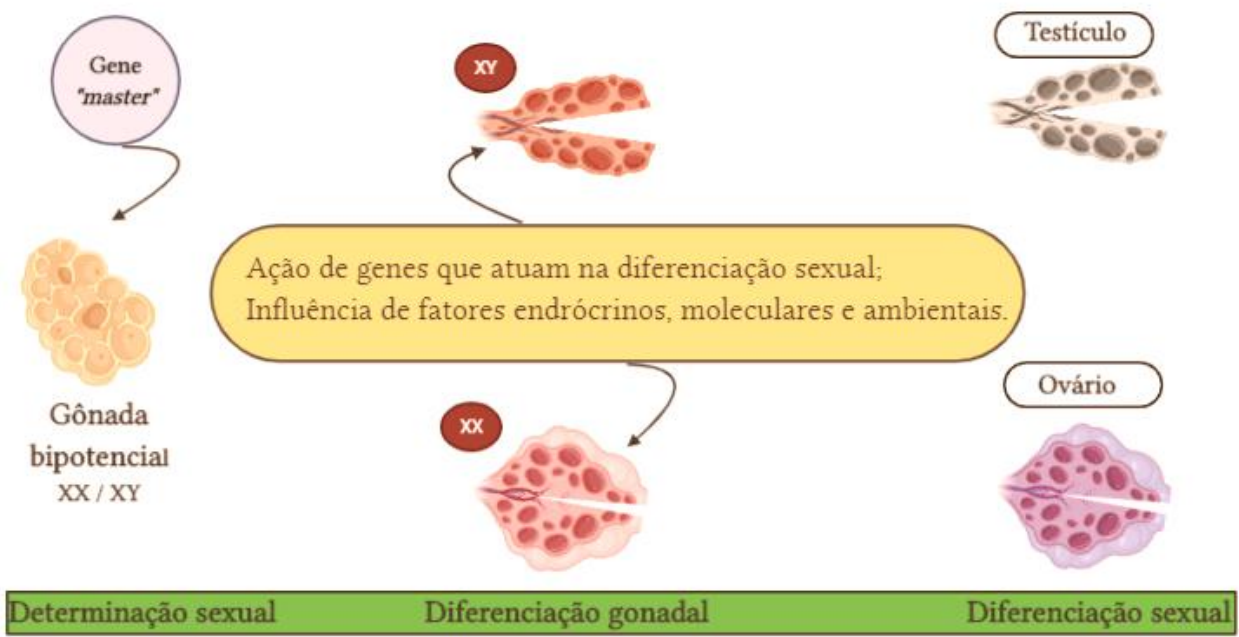

Figura 4. Representação da diferenciação sexual. Primeiramente a gônada bipotencial que apresenta células germinativas primordiais e células somáticas é determinada geneticamente (XX ou XY). Após esta etapa a gônada indiferenciada nos machos $\mathrm{XY}$ passam por uma baixa taxa de proliferação das células germinativas enquanto que nas fêmeas XX, ocorre o oposto. Neste momento, a gônada está sujeita a sinais ambientais (temperatura, hormônios, dentre outros) e também moleculares, como a expressão de genes relacionados a diferenciação sexual (por exemplo o $a m h$ ) tanto para macho como para fêmeas que atuam na diferenciação gonadal. Ainda na 
diferenciação gonadal, os animais machos XY apresentam um atraso na entrada da meiose enquanto a fêmeas XX dão início a meiose e oogênese e assim então, ocorre a diferenciação do sexo fenotípico nos animais com a formação de testículo nos machos e ovário nas fêmeas. Figura: Desenho pessoal.

No momento do desenvolvimento da gônada, as células germinativas precursoras irão se diferenciar na linhagem masculina ou feminina. Após esta etapa, estas células continuam a proliferar ou entram em meiose. Este último passo é muitas vezes sexo-específico, por exemplo, células germinativas femininas entram em meiose primeiro que as células da linhagem masculina (45). Esta observação é claramente descrita em estudos envolvendo o peixe medaka (46). Saito e colaboradores (46) mostram que o número de PGCs é independente do sexo durante a embriogênese final. No entanto, as PGCs começam a proliferar primeiramente nos embriões do sexo feminino, entrando em meiose mais precocemente do que nos machos (próximo do estágio de eclosão). Nos embriões do sexo masculino, a proliferação das PGCs ocorre tardiamente, porém se estende por um período maior após a eclosão (15 a 20 dias pós-eclosão) (46). Desta forma, pode-se dizer que o número de PGCs é influenciado pelo genótipo (XX ou XY) da espécie em questão.

Se avaliarmos a questão de que os genes "masters" de determinação sexual, gsdf" em Oryzia luzonensis (47), amhrII em fugu (48) e amhy em Odontesthes hatcheri (49) são genes de ação direta na proliferação e diferenciação das células germinativas nos peixes (50), é possível que a quantidade de células germinativas possa interferir no processo de diferenciação sexual gonadal em peixes (38,51-53).

\section{Genes "masters" na determinação e diferenciação sexual em peixes teleósteos}

Nos últimos anos, pesquisadores ao redor do mundo não mediram esforços para encontrar genes responsáveis pela determinação e diferenciação sexual nos peixes. Neste sentido, uma notável diversidade de genes "masters" determinantes do sexo, que governam as hierarquias genéticas tornou-se visível (9).

Em truta arco-íris o gene $s d Y$ foi descoberto como sendo o gene responsável pela determinação sexual nesta espécie (54). Em fugu (Takifugu rubripes), foi descrito o receptor tipo 2 do amh (amhrII) como o gene responsável pela determinação sexual. Neste trabalho os autores mostram que o polimorfismo em apenas um nucleotídeo é responsável pela determinação do sexo nesta espécie (55). O estudo realizado por Hattori e seus colaboradores (56) mostram evidencias funcionais da duplicação do gene amh, o amhy em O. hatcheri. Os autores sugerem que o amhy é o gene "master" responsável pela determinação sexual masculina nesta espécie. Além disso, o amhy está inteiramente conservado e ligado a determinação e diferenciação sexual em machos do gênero Odontesthes $(O$. argentinensis, $O$. incisa, O. mauleanum, O. perugiae, O. piquava, O. regia, and O. smitti, O. humensis, $O$. mirinensis, e O. nigricans) (57). Já em O. luzonensis, Myosho e colaboradores (47) identificaram o gene gsdfy como sendo o gene "master" de determinação sexual masculina.

$\mathrm{O}$ fato do Amh estar ligado à diferenciação sexual em peixes teleósteos foi observado em estudos realizados num mutante do peixe medaka, chamado hotei (58). O fenótipo hotei é causado pela mutação no gene que codifica o receptor do amh tipo II (amhrII). Nestes mutantes, a ausência do amhrII levou a uma hipertrofia gonadal e 50\% dos machos XY reverteram para fêmeas (58). Estes resultados sugerem que o AmhrII desempenha relevante papel na diferenciação sexual desta espécie. Além disso, também é sugerido que a sinalização do Amh regula a atividade proliferativa das células germinativas.

Nos peixes teleósteos, a expressão do amh é maior em machos do que em fêmeas, como por exemplo, em linguado (59), tilápia do Nilo (24) e zebrafish (60). Já em hermafroditas, 
como no pargo preto (Acanthopagrus schlegeli), por exemplo, níveis elevados de amh estão associados com o início da diferenciação testicular (59), e seu padrão de expressão é mantido durante o período de reversão sexual de fêmea para macho. Por outro lado, na reversão de macho para fêmea, seus níveis diminuem drasticamente $(59,60)$.

Em O. hatcheri, Hattori e colaboradores (50) mostraram que machos apresentam uma cópia duplicada do gene amh, o amhy, que está ligado ao cromossomo $\mathrm{Y}$ e é requerido para a determinação sexual desta espécie. Neste sentido, o amh e seu receptor devem desempenhar um papel importante na diferenciação sexual masculina, assim como no desenvolvimento testicular dos vertebrados de uma maneira geral.

Ao considerar conjuntamente os genes "master" de determinação sexual acima, é notória a importância de fatores de crescimento pertencentes a sinalização da superfamília TGF- $\beta$ (amh, amhrII, amhy e $g s d f^{y}$ ) nos mecanismos de determinação e diferenciação sexual em peixes. Ademais estes dados sugerem que os mecanismos de determinação sexual em peixes não são conservados e nem dependentes de fatores de transcrição. Porém, os componentes moleculares da via que determina o sexo são bastante conservados em relação aos mecanismos desencadeadores no topo da cascata $(2,5,9,56)$.

Informações a respeito dos mecanismos de ação de diferentes genes na determinação e diferenciação sexual ainda não foram completamente elucidados. Neste sentido, estudos sobre o papel dos genes com função nestes dois importantes processos poderão gerar conhecimentos para toda a cadeia aquícola.

\section{CONSIDERAÇÕES FINAIS}

Esta revisão buscou explicitar a respeito de como ocorre o processo de determinação e diferenciação sexual em vertebrados, dando ênfase no grupo dos peixes teleósteos. Os peixes são excelentes modelos biológicos para se estudar a determinação e diferenciação sexual, devido a sua plasticidade gonadal. Esses vertebrados utilizam uma ampla variedade de genes determinantes do sexo bem como mecanismos para controlar a diferenciação sexual. Por exemplo, algumas espécies usam o sistema genético que determina o sexo após a fertilização; enquanto outras utilizam sinais extrínsecos (temperatura, exposições a hormônios e poluentes). Desta forma, a determinação e diferenciação sexual é guiada por forças genéticas (processos biológicos e celulares) e/ou ambientais que determinarão se um peixe vai se tornar macho ou uma fêmea.

De uma maneira geral, é evidente que o processo de determinação e diferenciação sexual é mais complexo do que se imagina, uma vez que a cascata gênica envolvida nestes processos é altamente complexa.

\section{REFERÊNCIAS}

1. Hofsten JV, Olsson P-E. Zebrafish sex determination and differentiation: involvement of FTZ-F1 genes. Reprod Biol Endocrinol [Internet]. 2005 [citado 24 Maio 2021];3(1):1-11. Disponível em: https://www.ncbi.nlm.nih.gov/pmc/articles/PMC1298332/

2. Trukhina AV, Lukina NA, Wackerow-Kouzova ND, Smirnov AF. The variety of vertebrate mechanisms of sex determination. BioMed Res Int. 2013;2013:587460. doi: $10.1155 / 2013 / 587460$.

3. Graves JAM. How to evolve new vertebrate sex determining genes. Dev Dyn. 2013;242(4):354-9. doi: 10.1002/dvdy.23887. 
4. Kikuchi K, Hamaguchi S. Novel sex-determining genes in fish and sex chromosome evolution. Dev Dyn. 2013;242(4):339-53. doi: 10.1002/dvdy.23927.

5. Herpin A, Adolfi MC, Nicol B, Hinzmann M, Schmidt C, Klughammer J, et al. Divergent expression regulation of gonad development genes in medaka shows incomplete conservation of the downstream regulatory network of vertebrate sex determination. Mol Biol Evol. 2013;30(10):2328-46. doi: 10.1093/molbev/mst130.

6. Heule C, Salzburger W, Böhne A. Genetics of sexual development: an evolutionary playground for fish. Genetics. 2014;196(3):579-91. doi: 10.1534/genetics.114.161158.

7. Devlin RH, Nagahama Y. Sex determination and sex differentiation in fish: an overview of genetic, physiological, and environmental influences. Aquaculture. 2002;208(3-4):364. doi: 10.1016/S0044-8486(02)00057-1.

8. Graham P, Penn JK, Schedl P. Masters change, slaves remain. BioEssays. 2003;25(1):1-4. doi: 10.1002/bies. 10207.

9. Herpin A, Schartl M. Plasticity of gene-regulatory networks controlling sex determination: of masters, slaves, usual suspects, newcomers, and usurpators. EMBO Reports. 2015;16(10):1260-74. doi: 10.15252/embr.201540667.

10. Munger SC, Capel B. Sex and the circuitry: progress toward a systems-level understanding of vertebrate sex determination. Wiley Interdiscip Rev Syst Biol Med. 2012;4(4):401-12. doi: 10.1002/wsbm.1172.

11. Koopman P. Sex determination: the power of DMRT1. Trends Genet. 2009;25(11):47981. doi: 10.1016/j.tig.2009.09.009.

12. Capel B. Sex in the 90s: SRY and the switch to the male pathway. Annu Rev Physiol. 1998;60:497-523. doi: 10.1146/annurev.physiol.60.1.497.

13. Temel SG, Gulten T, Yakut T, Saglam H, Kilic N, Bausch E, et al. Extended pedigree with multiple cases of XX sex reversal in the absence of SRY and of a mutation at the SOX9 locus. Sex Dev. 2007;1(1):24-34. doi: 10.1159/000096236.

14. Nishioka M, Miura I, Saitoh K. Sex chromosomes of rana rugosa with special reference to local differences in sex-determining mechanism. Sci Rep Lab Amphibian Biol [Internet]. 1993 [cited 24 Maio 2021];(12):55-8. Disponível em: https://ir.lib.hiroshimau.ac.jp/en/list/HU_journals/AA00837669/12/--/item/14532

15. Roco ÁS, Olmstead AW, Degitz SJ, Amano TA, Zimmerman LB, Bullejos M. Coexistence of $\mathrm{Y}, \mathrm{W}$, and $\mathrm{Z}$ sex chromosomes in Xenopus tropicalis. Proc Natl Acad Sci USA. 2015;112(34):e4752-61. doi: 10.1073/pnas.1505291112.

16. Yoshimoto S, Okada E, Umemoto H, Tamura K, Uno Y, C Nishida-Umehara C, et al. A W-linked DM-domain gene, DM-W, participates in primary ovary development in Xenopus laevis. Proc Natl Acad Scie USA. 2008;105(7):2469-74. doi: 10.1073/pnas.0712244105. 
17. Nanda I, Zend-Ajusch E, Shan Z, Grützner F, Schartl M, Burt DW, et al. Conserved synteny between the chicken $Z$ sex chromosome and human chromosome 9 includes the male regulatory gene DMRT1: a comparative (re)view on avian sex determination. Cytogenet Cell Genet. 2000;89(1-2):67-78. doi: 10.1159/000015567.

18. Smith CA, Roeszler KN, Ohnesorg T, Cummins DM, Farlie PG, Doran TJ, et al. The avian Z-linked gene DMRT1 is required for male sex determination in the chicken. Nature. 2009;461(7261):267-71. doi: 10.1038/nature08298.

19. Ayers KL, Sinclair AH, Smith CA. The molecular genetics of ovarian differentiation in the avian model. Sex Dev. 2013;7(1-3):80-94. doi: 10.1159/000342358.

20. Raymond CS, Shamu CE, Shen MM, Seifert KJ, Hirsch B, Hodgkin J, et al. Evidence for evolutionary conservation of sex-determining genes. Nature. 1998;391(6668):691-5. doi: $10.1038 / 35618$.

21. Huang S, Ye L, Chen H. Sex determination and maintenance: the role of DMRT1 and FOXL2. Asian J Androl. 2017;19(6):619-624. doi: 10.4103/1008-682X.194420.

22. Mello MP, Assumpção JG, Hackel C. Genes involved in sex determination and differentiation. Arq Bras Endocrinol Metab. 2005;49(1):14-25. doi: 10.1590/S000427302005000100004.

23. Marchand O, Govoroun M, D'Cotta H, McMeel O, Lareyre JJ, Bernot A, et al. DMRT1 expression during gonadal differentiation and spermatogenesis in the rainbow trout, Oncorhynchus mykiss. Biochim Biophys Acta. 2000;1493(1-2):180-7. doi: 10.1016/S0167-4781(00)00186-X.

24. Ijiri S, Kaneko H, Kobayashi T, Wang DS, Sakai F, Paul-Prasanth B, et al. Sexual dimorphic expression of genes in gonads during early differentiation of a teleost fish, the Nile tilapia Oreochromis niloticus. Biol Reprod. 2008;78(2):331-41. doi: 10.1095/biolreprod.107.064246.

25. Guo Y, Cheng H, Huang X, Gao S, Yu H, Zhou R. Gene structure, multiple alternative splicing, and expression in gonads of zebrafish Dmrt1. Biochem Biophys Res Commun. 2005;330(3):950-7. doi: 10.1016/j.bbrc.2005.03.066.

26. Webster KA, Schach U, Ordaz A, Steinfeld JS, Draper BW, Siegfried KR. Dmrt1 is necessary for male sexual development in zebrafish. Dev Biol. 2017;422(1):33-46. doi: 10.1016/j.ydbio.2016.12.008.

27. Lin Q, Mei J, Li Z, Zhang X, Zhou L, Gui JF. Distinct and cooperative roles of amh and dmrtl in self-renewal and differentiation of male germ cells in zebrafish. Genetics. 2017;207(3):1007-22. doi: 10.1534/genetics.117.300274.

28. Matsuda M, Nagahama Y, Shinomiya A, Sato T, Matsuda C, Kobayashi T, et al. DMY is a Y-specific DM-domain gene required for male development in the medaka fish. Nature [Internet]. 2002 [citado 24 Maio 2021];417(6888):559-63. Disponível em: https://www.nature.com/articles/nature751 
29. Nanda I, Kondo M, Hornung U, Asakawa S, Winkler C, Shimizu A, et al. A duplicated copy of DMRT1 in the sex-determining region of the Y chromosome of the medaka, Oryzias latipes. Proc Natl Acad Sci USA. 2002;99(18):11778-83. doi: 10.1073/pnas.182314699.

30. Kang Y, Guan GJ, Hong YH. Insights of sex determination and differentiation from medaka as a teleost model. Yi Chuan $=$ Hereditas. 2017;39(6):441-454. doi: 10.16288/j.yczz.17-140.

31. Matsuda M, Matsuda C, Hamaguchi S, Sakaizumi M. Identification of the sex chromosomes of the medaka, Oryzias latipes, by fluorescence in situ hybridization. Cytogenet Cell Genet. 1998;82(3-4):257-62. doi: 10.1159/000015113.

32. Thorgaard GH. Heteromorphic sex chromosomes in male rainbow trout. Science. 1977;196(4292):900-2. doi: 10.1126/science.860122.

33. Iturra P, Lam N, de la Fuente M, Vergara N, Medrano JF. Characterization of sex chromosomes in rainbow trout and coho salmon using fluorescence in situ hybridization (FISH). Genetica [Internet]. 2001 [citado 24 Maio 2021];111(1-3):125-31. Disponível em: https://link.springer.com/article/10.1023/A:1013725717142

34. Baroiller JF, D'Cotta H, Saillant E. Environmental effects on fish sex determination and differentiation. Sex Dev. 2009;3(2-3)118-35. doi: 10.1159/000223077.

35. Mair GC, Scott AG, Penman DJ, Skibinski DO, Beardmore JA. Sex determination in the genus Oreochromis : 2. Sex reversal, hybridisation, gynogenesis and triploidy in $\mathrm{O}$. aureus Steindachner. Theor Appl Genet [Internet]. 1991 [citado 24 Maio 2021];82(2):153-60. Disponível em: https://pubmed.ncbi.nlm.nih.gov/24213059/

36. Volff JN, Schartl M. Variability of genetic sex determination in poeciliid fishes. Genetica [Internet]. 2001 [citado 24 Maio 2021];111(1-3):101-10. Disponível em: https://link.springer.com/article/10.1023/A:1013795415808

37. Schartl M. A comparative view on sex determination in medaka. Mech Dev. 2004;121(78):639-45. doi: 10.1016/j.mod.2004.03.001.

38. Adolfi MC, Nakajima RT, Nobrega RH, Schartl M. Intersex, hermaphroditism, and gonadal plasticity in vertebrates: evolution of the Mullerian Duct and Amh/Amhr2 signaling. Annu Rev Anim Biosci. 2019;7:149-72. doi: 10.1146/annurev-animal-020518114955.

39. Valenzuela N, Adams DC, Janzen FJ. Pattern does not equal process: exactly when is sex environmentally determined? Am Nat. 2003;161(4):679-83. doi: 10.1086/368292.

40. Hayashi Y, Kobira H, Yamaguchi T, Shiraishi E, Yazawa T, Hirai T, et al. High temperature causes masculinization of genetically female medaka by elevation of cortisol. Mol Reprod Dev. 2010;77(8):679-86. doi: 10.1002/mrd.21203. 
41. Yamaguchi T, Yoshinaga N, Yazawa T, Gen K, Kitano T. Cortisol is involved in temperature-dependent sex determination in the Japanese flounder. Endocrinology. 2010;151(8):3900-8. doi: 10.1210/en.2010-0228.

42. Raz E. Primordial germ-cell development: the zebrafish perspective. Nat Rev Genet. 2003;4(9):690-700. doi: 10.1038/nrg1154.

43. Raz E, Reichman-Fried M. Attraction rules: germ cell migration in zebrafish. Curr Opin Genet Dev. 2006;16(4):355-9. doi: 10.1016/j.gde.2006.06.007.

44. Guerrero-Estévez S, Moreno-Mendoza N. Sexual determination and differentiation in teleost fish. Rev Fish Biol Fish. 2009;20(1):101-21.

45. Kimble J, Page DC. The mysteries of sexual identity. The germ cell's perspective. Science. 2007;316(5823):400-1. doi: 10.1007/s11160-009-9123-4.

46. Saito D, Morinaga C, Aoki Y, Nakamura S, Mitani H, Furutani-Seiki, et al. Proliferation of germ cells during gonadal sex differentiation in medaka: insights from germ celldepleted mutant zenzai. Dev Biol. 2007;310(2):280-90. doi: 10.1016/j.ydbio.2007.07.039.

47. Myosho T, Otake H, Masuyama H, Matsuda M, Kuroki Y, Fujiyama A, et al. Tracing the emergence of a novel sex-determining gene in Medaka, Oryzias Luzonensis. Genetics. 2012;191(1):163-70. doi: 10.1534/genetics.111.137497.

48. Kamiya T, Kai W, Tasumi S, Oka A, Matsunaga T, Mizunio N, et al. A trans-species missense SNP in Amhr2 is associated with sex determination in the tiger pufferfish, Takifugu rubripes (fugu). PLoS Genet [Internet]. 2012 [citado 24 Maio 2021];8(7):e1002798. Disponível em: https://journals.plos.org/plosgenetics/article?id=10.1371/journal.pgen.1002798

49. Hattori RS, Murai Y, Oura M, Matsuda S, Majhi SK, Sakamoto T, et al. A Y-linked antiMüllerian hormone duplication takes over a critical role in sex determination. Proc Natl Acad Sci USA. 2012;109(8):2955-9. doi: 10.1073/pnas.1018392109.

50. Gautier A, Le Gac F, Lareyre JJ. The gsdf gene locus harbors evolutionary conserved and clustered genes preferentially expressed in fish previtellogenic oocytes. Gene. 2011;472(1-2):7-17. doi: 10.1016/j.gene.2010.10.014.

51. Herpin A, Schartl M. Molecular mechanisms of sex determination and evolution of the Y-chromosome: insights from the medakafish (Oryzias latipes). Mol Cell Endocrinol. 2009;306(1-2):51-8. doi: 10.1016/j.mce.2009.02.004.

52. Nakamura S, Watanabe I, Nishimura T, Picard JY, Toyoda A, Taniguchi Y, et al. Hyperproliferation of mitotically active germ cells due to defective anti-Müllerian hormone signaling mediates sex reversal in medaka. Development. 2012;139(13):2283-7. doi: $10.1242 /$ dev.076307.

53. Kurokawa H, Saito D, Nakamura S, Katoh-Fukui Y, Ohta K, Baba T, et al. Germ cells are essential for sexual dimorphism in the medaka gonad. Proc Natl Acad Sci USA. 2007;23;104(43):16958-63. doi: 10.1073/pnas.0609932104. 
54. Yano A, Guyomard R, Nicol B, Jouanno E, Quillet E, Klopp C, et al. An immune-related gene evolved into the master sex-determining gene in rainbow trout, Oncorhynchus mykiss. Curr Biol. 2012;22(15):1423-8. doi: 10.1016/j.cub.2012.05.045.

55. Hattoti RS, Somoza GM, Fernandino JI, Colautti DC, Miyoshi K, Gong Z, et al. The duplicated Y-specific amhy gene is conserved and linked to maleness in silversides of the genus Odontesthes. Genes. 2019;10(9):679. doi: 10.3390/genes10090679.

56. Morinaga C, Saito D, Nakamura S, Sasaki T, Asakawa S, Shimizu N, et al. The hotei mutation of medaka in the anti-Mullerian hormone receptor causes the dysregulation of germ cell and sexual development. Proc Natl Acad Sci USA. 2007;104(23)9691-6. doi: 10.1073/pnas.0611379104.

57. Yoshinaga N, Shiraishi E, Yamamoto T, Iguchi T, Abe S, Kitano T. Sexually dimorphic expression of a teleost homologue of Müllerian inhibiting substance during gonadal sex differentiation in Japanese flounder, Paralichthys olivaceus. Biochem Biophys Res Commun. 2004;322(2):508-13. doi: 10.1016/j.bbrc.2004.07.162.

58. Rodrígues-Marí A, Yan YL, Bremiller RA, Wilson C, Cañestro C, Postlehwait JH. Characterization and expression pattern of zebrafish Anti-Müllerian hormone (Amh) relative to sox9a, sox9b, and cyp19a1a, during gonad development. Gene Expr Patterns. 2005;5(5):655-67. doi: 10.1016/j.modgep.2005.02.008.

59. Wu GC, Chiu PC, Lyu YS, Chang CF. The expression of amh and amhr2 is associated with the development of gonadal tissue and sex change in the protandrous black porgy, Acanthopagrus schlegeli. Biol Reprod. 2010;83(3):443-53. doi: 10.1095/biolreprod.110.084681.

60. Wu GC, Chang CF. The switch of secondary sex determination in protandrous black porgy, Acanthopagrus schlegeli. Fish Physiol Biochem. 2013;39(1):33-8. doi: 10.1007/s10695-012-9618-0. 